\title{
PENYEBAB IMPLIKATUR PERCAKAPAN WACANA HUMOR BERBAHASA JAWA PADA RUBRIK THENGIL DI MAJALAH ANCAS
}

\section{THE CAUSES OF IMPLICATURES IN JAVANESSE LANGUAGE DISCOURSE CONVERSATIONS ONTHENGIL RUBRIC ANCAS MAGAZINE}

\author{
Imaniah Kusuma Rahayu \\ Universitas Timor \\ niah.ima76@gmail.com
}

\begin{abstract}
Abstrak
Penelitian ini bertujuan memaparkan penyebab implikatur pada rubrik Thengil di majalah Ancas. Data dikumpulkan dengan metode simak dan teknik catat. Analisis data dilakukan dengan menggunakan metode pragmatis dengan teknik heuristik. Pendekatan penelitian yang digunakan adalah pendekatan metodologis dan teoretis. Data yang telah dianalisis kemudian disajikan secara informal. Penyajian data secara informal dapat dilakukan dengan cara menggunakan kata-kata. Penyebab implikatur yang ditemukan dalam penelitian ini adalah Pelanggaran Prinsip Kerja Sama dan Prinsip Kerukunan. Pelanggaran Prinsip Kerja Sama meliputi (1) Pelanggaran bidal Kuantitas; (2) Pelanggaran bidal Kualitas; (3) Pelanggaran Bidal Relevansi; (4), Pelanggaran Bidal Cara. Pelanggaran prinsip kerukunan meliputi (1) Pelanggaran bidal kurmat (hormat), (2) Pelanggaran bidal andhap asor (rendah hati), (3) Pelanggaran bidal empan papan (sadar akan tempat), dan (4) Pelanggaran bidal tepa selira (tenggang rasa). Penyebab implikatur yang ditemukan tersebut dapat berfungsi sebagai penunjang kelucuan pada humor tersebut.

Kata kunci: penyebab implikatur, prinsip percakapan, wacana bumor..
\end{abstract}

\begin{abstract}
The purpose of the research is to explain the causes of implication in the rubric Thengil in the Ancas magazine. The collection data use refer method $\mathrm{n}$ written method. The analyze data use heuristic method $\mathrm{n}$ pragmatic method. Research approach is using methodologic theory. The data has been analyze then presented informally. Informal presentation data can be doneby using words. The cause implication found in this study are violations of the principle of coorperation and the principle of harmony. Violation of the principle of coorperation includees: violation of quantity thimble, violation of quality thimble, violation of thimble relevance, and violation of the way thimble. The violation principle of harmony includes:violation of respectful thimbles, violation of humble thimbles, violation of place aware of thimbles, and violation of tolerant thimbles. The cause implication found can serve as support for funny humor.
\end{abstract}

Keywords: the causes of implicatures, the principle of conversation, humourous discourse

\section{PENDAHULUAN}

Humor adalah suatu keadaan atau gejala yang dapat menimbulkan efek tertawa merupakan suatu unsur yang sering dijumpai dalam kehidupan sehari-hari. Humor tidak mengenal kelas sosial, latar pendidikan, dan tingkat intelegensi manusia. Tuturan yang mengandung humor dapat mengurangi berbagai ketegangan. Wijana (2002:77) memberi 
penjelasan bahwa berbicara secara wajar pada hakikatnya berbeda dengan berbicara dalam rangka humor.

Humor dapat tampil mantap sebagai penyegar pikiran sekaligus sebagai penyejuk batin, serta penyalur uneg-uneg. Humor dapat juga memberikan suatu wawasan yang arif sambil tetap menghibur. Selain itu, dapat pula menyampaikan siratan menyindir atau suatu kritikan yang bernuansa tawa. Humor juga dapat sebagai sarana persuasi untuk mempermudah masuknya informasi atau pesan yang ingin disampaikan sebagai suatu yang serius dan formal.

Wacana humor yang terdapat pada rubrik Thengil majalah Ancas menarik untuk diteliti karena diduga memiliki berbagai fenomena kebahasaan. Salah satunya adalah bahasa dalam wacana humor bila dipandang dari sudut pragmatik mempunyai sifat kepragmatikan yang beragam. Keanekaragaman ini meliputi berbagai fenomena kebahasaan dan pragmatik seperti tindak tutur, prinsip kerja sama, prinsip kesantunan, prinsip kerukunan, dan implikatur

Implikatur terjadi karena ada pelanggaran prinsip percakapan. Prinsip percakapan merupakan prinsip yang mengatur proses percakapan agar berlangsung lancar dan santun. Percakapan bisa berlangsung dengan baik ketika terjadi koherensi atau kerja sama yang baik dalam proses percakapan. Prinsip tersebut dikenal dengan prinsip kerja sama. Prinsip kerja sama sebagai kaidah percakapan dimaksudkan sebagai upaya membimbing pemakai bahasa agar dapat menggunakan bahasa secara efektif dan efisien di dalam melakukan percakapan. Grice (dalam Rustono 1999:58) menyertakan prinsip empat bidal dasar percakapan sebagai tuntunan ke arah kerja sama efektif dalam penggunaan bahasa, atau yang lebih dikenal dengan prinsip kerja sama yaitu (1) bidal kuantitas (2) bidal kualitas (3) bidal relevansi (4) bidal cara. Akan tetapi, ternyata prinsip kerja sama itu banyak dilanggar oleh para pelaku humor di dalam jenis wacana humor ini. Pelanggaran prinsip kerja sama ini bertujuan untuk menunjang kelucuan humor pada wacana tersebut.

Fungsi utama komunikasi salah satunya adalah untuk menjaga keberlangsungan hubungan antara komunikannya. Oleh karena itu, bahasa yang merupakan alat komunikasinya berisi kaidah-kaidah yang mengatur bagaimana cara seseorang bertutur agar hubungan interpersonal para pemakai bahasa tersebut dapat terpelihara dengan baik. Dalam kaitan ini, masyarakat pengguna bahasa, dalam situasi tertentu dan untuk mencapai tujuan tertentu, akan selalu berusaha memilih dan menggunakan kaidah-kaidah tuturan (utterance) yang sesuai dengan situasi pertuturan agar peserta tutur dapat saling berinteraksi, dan bentuk tuturnya menjadi saling terpahami. Pemahaman terhadap tutur tersebut, dimungkinkan karena adanya pengetahuan bersama (shared knowledge) diantara penutur dan petutur.

Kaidah-kaidah dalam tata cara berkomunikasi, berbeda antara suatu masyarakat dengan masyarakat lainnya. Dalam studi sosio-pragmatik, dapat dilihat bahwa strategi bertutur yang disebut dengan retorika dalam prinsip sopan santun, pada kebudayaankebudayaan dan masyarakat bahasa berbeda misalnya, akan beroperasi secara berbeda (Leech 1993:15). Sebagai contoh, dalam masyarakat Jawa yang memiliki tingkat tutur 'unggah-unggub' (ngoko, madya atau krama inggil), penggunaannya dipilih penutur ketika berbicara dengan petutur sesuai dengan situasi interaksi tertentu. 
Prinsip percakapan yang kedua melibatkan tingkat kesantunan biasa dikenal dengan prinsip kesantunan. Gunarwan (dalam Pranowo 2012:47) merujuk pada hasil penelitian Geertz (dalam Suseno 1985:38) mengemukakan prinsip kerukunan sebagai prinsip kesantunan berbahasa bagi masyarakat Jawa. Berbeda dengan Geerts, Gunarwan memasukkan prinsip hormat (kurmat) sebagai salah satu bidal dari prinsip kerukunan. Gunarwan (dalam Pranowo 2012:47) berasumsi bahwa pada dasarnya hanya ada satu prinsip penting yang diikuti dalam masyarakat budaya Jawa yaitu prinsip keseimbangan. Prinsip keseimbangan ini diasumsikan bertumpu kepada asas kerukunan sehingga prinsip keseimbangan ini isomorfis dengan prinsip kerukunan yang esensinya untuk menghindari konflik. Prinsip kerukunan yang diajukan Gunarwan (104:2007) terdiri atas empat bidal, yaitu bidal kurmat (hormat), andhap asor (rendah hati), empan papan (sadar akan tempat), dan tepa salira (tenggang rasa). Jadi, semakin santun tuturan seseorang semakin baik pula kualitas percakapan tersebut.

Kegiatan percakapan berlangsung dengan sangat baik apabila kedua prinsip percakapan, prinsip kerja sama dan prinsip kesantunan dipatuhi atau dijalankan oleh tiaptiap peserta tutur. Dalam wacana humor berbahasa Jawa rubrik Thengil terdapat pematuhan dan juga pelanggaran terhadap prinsip percakapan tersebut. Tuturan-tuturan yang diduga melanggar prinsip kerja sama dan prinsip kesantunan dalam wacana humor berbahasa Jawa terkadang sengaja dilakukan untuk menciptakan kelucuan.

Dipilihnya majalah Ancas sebagai sumber data penelitian ini, dikarenakan majalah Ancas adalah majalah yang dapat menghibur sekaligus mendidik para pembacanya tentang kehidupan sehari-hari. Majalah Ancas merupakan satu-satunya majalah berbahasa Jawa dengan dialek Banyumas yang memberikan daya tarik tersendiri bagi pembacanya serta dapat memelihara kebudayaan yang berupa bahasa daerah. Majalah Ancas terbit satu kali dalam satu bulan. Di setiap edisinya disajikan informasi-informasi yang terbaru dengan fenomena-fenomena yang terjadi di kehidupan sehari-hari dalam masyarakat. Akan tetapi penelitian ini dikhususkan pada humor yang terdapat dalam majalah Ancas, karena humor yang disajikan dalam majalah Ancas ini dirasa dapat memberikan pengetahuan kepada pembacanya. Kelucuan rubrik muncul karena hal-hal yang sebenarnya tampak sederhana tetapi mengesankan kebodohan, kekonyolan, ketidaktahuan atau bahkan ketidaksengajaan para penuturnya. Berdasarkan alasan tersebut peneliti tertarik untuk meneliti lebih jauh tentang wacana humor di majalah Ancas mengenai penyebab implikatur yaitu pelanggaran prinsip kerja sama, dan pelanggaran prinsip kerukunan bagi masyarakat Jawa.

\section{METODE PENELITIAN}

Pendekatan yang digunakan dalam penelitian ini ada dua yaitu pendekatan teoritis dan pendekatan metodologis. Pendekatan teoritis yang digunakan adalah pendekatan pragmatis. Pendekatan pragmatis digunakan untuk menganalisis implikatur. Pendekatan metodologis dalam penelitian ini adalah pendekatan deskriptif dan pendekatan kualitatif. Teknik pengumpulan data yang digunakan dalam penelitian ini adalah teknik simak dan teknik catat. Peneliti menyimak penggunaan bahasa dalam rubrik Thengil di majalah Ancas. Setelah dilakukan penyimakan kemudian dilakukan pencatatn terhadap data yang diperoleh. Data yang telah didapat diuji keabsahannya menggunakan teknik triangulasi dan kemudian 
data tersebut dianalisis dengan menggunakan metode pragmatis teknik heuristik. Data yang telah dianalisis kemudian disajikan secara informal. Penyajian data secara informal dapat dilakukan dengan cara menggunakan kata-kata.

\section{HASIL DAN PEMBAHASAN}

\section{Pelanggaran Prinsip Kerja sama}

Sesuai dengan data penelitian, pelanggaran prinsip kerja sama pada rubrik Thengil di majalah Ancas diklasifikasikan menjadi empat. Keempat jenis pelanggaran prinsip kerja sama tersebut dipaparkan secara rinci sesuai data penelitian yang ada sebagai berikut.

\section{Pelanggaran Bidal Kuantitas}

Bidal kuantitas adalah bidal yang berisi nasihat yang menyangkut jumlah kontribusi yang disumbangkan oleh para peserta percakapan terhadap koherensi percakapan. Subbidal yang diturunkan dari bidal ini adalah buatlah sumbangan atau kontribusi Anda seinformatifinformatifnya sesuai dengan yang diperlukan (untuk maksud percakapan). Maksud subbidal ini adalah bahwa kontribusi tiap-tiap penutur di dalam percakapan hendaknya tepat sesuai dengan kebutuhan yang diperlukan secara kuantitatif. Dalam wacana humor berbahasa Jawa rubrik Thengil pada majalah Ancas terdapat pelanggaran terhadap bidal ini. Pelanggaran terhadap bidal ini cenderung berfungsi sebagai penunjang humor karena melalui inferensi yang ditarik atas pelanggaran bidal ini dapat diketahui adanya implikatur tertentu. Pelanggaran bidal kuantitas sebagai penunjang humor terdapat dalam penggalan wacana berikut.

$\begin{aligned} & \text { (1) KONTEKS : } \text { GUPLO BERTANYA KEPADA GESENG KENAPA } \\ & \text { IA TERLIHAT TERENGAH-ENGAH SEPERTI } \\ & \text { HABIS BERLARI-LARI. } \\ & \text { Guplo } \quad \text { Rika kenangapa deneng menggeh-menggeh kaya bar deudag-udag } \\ & \text { celeng. Kang? } \\ & \text { 'Kamu kenapa kok ngos-ngosan seperti habis dikejar- } \\ & \text { kejar babi, Kang?' } \\ &: \text { Bocah maning, inyong genah tes deudag-udag } \\ & \text { celeng } \text { koh. Inyong meh bae } \text { kesruduk. Untunge } \\ & \text { celenge bola-bali } \text { kepleset, dadi inyong bisa mlayu } \\ & \text { lewih adoh. } \\ & \text { 'Dasar bocah, saya memang habis dikejar-kejar babi. Saya } \\ & \text { hampir saja disruduk. Untung babinya bolak-balik } \\ & \text { terpeleset, jadi saya bisa berlari lebih jauh.' }\end{aligned}$

Tuturan Geseng di dalam penggalan wacana (1) melanggar bidal kuantitas karena tuturan itu secara kuantitas berlewah. Kontribusi yang disumbangkan Geseng di dalam penggalan wacana itu tidak sesuai dengan yang dibutuhkan, yaitu terlalu banyak. Sementara itu, Guplo, mitra tuturnya, hanya memberikan sedikit kontribusi terhadap berlangsungnya percakapan itu. Jika tuturan Geseng itu hanya berbunyi, 'Inyong genah bar deudag-udag celeng' 
(Saya memang habis dikejar-kejar babi), tuturan itu tentu tidak melanggar bidal kuantitas karena kontribusi itu memadai.

Tuturan Geseng yang melanggar bidal kuantitas memiliki fungsi sebagai penunjang humor. Kelucuan yang tercipta dengan adanya tuturan Geseng di dalam penggalan wacana (1) itu ditunjang oleh implikatur yang dapat ditarik atas pelanggaran bidal kuantitas itu. Inferensi yang dapat ditarik atas pelanggaran bidal kuantitas itu menghasilkan simpulan bahwa Geseng itu tidak mematuhi bidal kuantitas karena ada implikatur bahwa dirinya kesal. Implikatur kesal dinyatakan secara tersirat oleh Geseng melalui tuturan yang memberondong tersebut.

\section{Pelanggaran Bidal Kualitas}

Berbeda dari bidal kuantitas yang menyangkut jumlah kontribusi, bidal kualitas berkenaan dengan kualitas kontribusi penutur di dalam percakapan. Bidal ini berisi nasihat bahwa penutur hendaknya memberikan kontribusi yang benar dengan bukti-bukti yang dapat dipertanggungjawabkan di dalam melakukan percakapan. Jangan mengatakan sesuatu yang Anda yakini salah dan jangan mengatakan sesuatu yang buktinya tidak Anda miliki adalah dua subbidal sebagai jabaran dari bidal ini. Maksud dua subbidal ini adalah bahwa tiap-tiap penutur di dalam percakapan harus mengatakan hal yang benar dengan dasar bukti-bukti yang memadai. Pelanggaran bidal kualitas sebagai penunjang humor terdapat dalam penggalan wacana berikut.

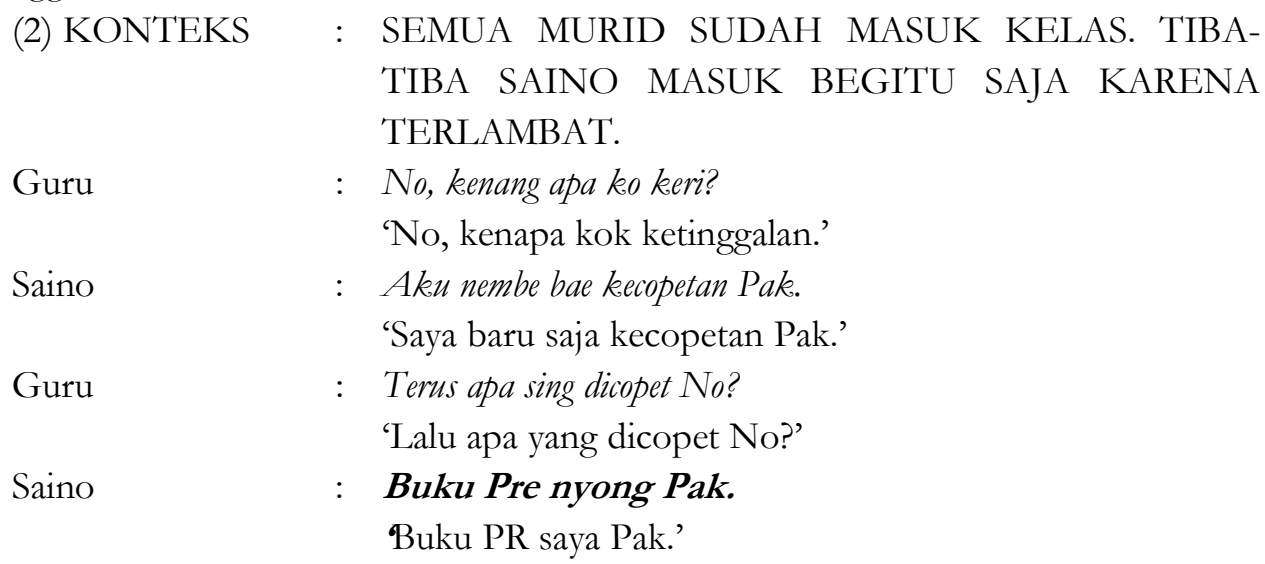

Di dalam akhir penggalan wacana (2) tuturan Saino melanggar bidal kualitas karena isinya secara kualitas tidak benar. Kebenaran buku PR Saino yang dicopet tidak dapat dibuktikan. Pencopet biasanya akan mencopet barang-barang berharga bukannya buku PR. Karena tidak didukung oleh bukti, tuturan Saino di dalam penggalan wacana (2) itu melanggar bidal kualitas. Seandainya berbunyi "Tase nyong Pak" (Tas saya Pak) tuturan itu tidaklah melanggar bidal kualitas karena memang benar tas biasanya digunakan untuk menyimpan barang-barang berharga ketika berpergian. Ada kemungkinan kalau tas yang dicopet itu benar karena di dalam tas ada barang berharga.

Tuturan Saino yang melanggar bidal kualitas memiliki fungsi sebagai penunjang kelucuan. Humor yang tercipta dengan adanya tuturan Saino di dalam penggalan wacana (2) itu ditunjang implikatur yang dapat ditarik atas pelanggaran bidal kualitas itu. Inferensi yang 
dilakukan terhadap pelanggaran bidal itu menghasilkan simpulan bahwa tuturan itu tidak mematuhi bidal kualitas karena mengandung implikatur yaitu, berbohong. Implikatur berbohong dinyatakan secara tersirat oleh Saino melalui tuturan yang tidak benar.

\section{Pelanggaran Bidal Relevansi}

Bidal relevansi adalah bidal berisi nasihat bahwa penutur hendaknya bertutur tentang hal-hal yang relevan dengan topik percakapan yang sedang diikutinya. Bidal ini menekankan pada keterkaitan isi tuturan antarpeserta percakapan. Hasil yang diharapkan dari pematuhan bidal ini adalah koherensi percakapan dapat tercipta. Penutur saling memberikan kontribusi yang relevan dengan topik pembicaraan sehingga tujuan percakapan tercapai secara efektif. Pelanggaran bidal relevansi sebagai penunjang humor terdapat dalam penggalan wacana berikut.

$\begin{array}{ll}\text { (3) KONTEKS : } & \text { SELESAI BERBELANJA, SAYA KEMBALI KE } \\ & \text { PARKIRAN. SETELAH MEMAKAI MASKER, } \\ & \text { SARUNG TANGAN, KACAMATA, SAYA PUN } \\ & \text { MENCARI HELM UNTUK DIPAKAI. SAYA } \\ & \text { MENCARI HELM DAN DIBANTU OLEH TUKANG } \\ & \text { PARKIR. TUKANG PARKIR PURA-PURA IKUT } \\ & \text { MENCARI HELM PADAHAL IA SUDAH MELIHAT } \\ & \text { HELM IBU TERSEBUT. } \\ & : \text { Kenang ngapa yu? Nggoleti apa? } \\ & \text { 'Ada apa Mba? Mencari apa?.' } \\ \text { Tukang Parkir: } & : \text { Helm. Ujarku mau tek bruk neng kene deneng langka. } \\ & \text { 'Helm. Saya kira tadi daya letakkan di sini kok tidak ada.' } \\ \text { Pembeli } & : \text { Nggoleti apa si yu? } \\ & \text { 'Mencari apa si mba?' } \\ \text { Pembeli lain } & : \text { Helm. } \\ \text { Pembeli } & \text { Lab kune mbok helme wis denggo. } \\ \text { Pembeli lain } & \text { 'Lha itu kan helmnya sudah dipakai.' } \\ & \text { Nggo tamba kencot yu... } \\ \text { Tukang parkir } & \text { 'Untuk mengobati rasa lapar Yu' }\end{array}$

Penggalan wacana (3) mengandung tuturan Tukang Parkir yang melanggar bidal relevansi. Alasannya adalah isi tuturan itu tidak relevan dengan topik pembicaraan yang dikembangkan mitra tuturnya, pembeli yang memarkirkan motornya di situ. Tuturan Ibu (pembeli) itu berisi pertanyaan tentang keberadaan helmnya sedangkan tuturan tukang parkir, sebagai jawaban atas pertanyaan Ibu itu berisi pernyataan dirinya yang lapar. Tidak ada kaitan antara keberadaan helm dengan kelaparan. Jawaban yang diharapkan tentu saja tentang keberadaan helm, bukan tentang rasa kelaparan yang dialami tukang parkir. Karena tidak berkaitan, tuturan tukang parkir di dalam penggalan wacana (3) itu melanggar bidal relevansi.

\section{Pelanggaran Bidal Cara}


Bidal yang berisi nasihat agar penutur mengatakan sesuatu dengan jelas adalah bidal cara. Tekanan bidal ini ada pada kejelasan tuturan. Untuk itu bidal ini dijabarkan lagi ke dalam empat subbidal, yaitu hindarkan ketidakjelasan tuturan, hindarkan ketaksaan, singkat, tertib, dan teratur (Rustono 1999:62). Realisasi bidal ini adalah penutur hendaknya berbicara secara langsung, tidak kabur, tidak taksa, tidak berlebihan, dan runtut. Bertutur dengan jelas berarti berbicara dengan suara yang dapat didengar dengan maksud yang mudah ditangkap. Pelanggaran bidal cara sebagai penunjang humor terdapat dalam penggalan wacana berikut.

(4) KONTEKS

Paino

Biyunge

Paino

Biyunge
: PAINO MEMBERITAHUKAN HASIL ULANGAN KEPADA IBUNYA. IBU MEMUJI PAINO KARENA HASIL ULANGANNYA BAGUS TIDAK SEPERTI BIASANYA YANG SELALU JELEK. TERNYATA SANG IBU SALAH SANGKA, HASIL ULANGAN PAINO TETAP SAJA JELEK.

: Inyong wingi ulangan olih biji 85, Yung. 'Kemarin saya ulangan mendapat nilai 85, Bu.'

: Alhamdulillah. Jan ora kaya anake inyong. Ulangan apa deneng maen temen bijine, No? 'Alhamdulillah. Jan tidak seperti anak saya. ulangan apa kok nilainya bagus, No?'

\section{: Ulangan basa Indonesia karo Matematika, Yung.}

'Ulangan basa Indonesia sama Mtematika.'

: Maksude rong pelajaran olih biji 85 kabeh apa kepriwe, No?

'Maksudnya dua mata pelajaran dapat 85 atau bagaimana, No?'

Di dalam penggalan wacana (4) terdapat tuturan yang melanggar bidal cara, yaitu tuturan Paino, "Ulangan basa Indonesia karo Matematika, Yung" (Ulangan bahasa Indonesia dan Matematika $\mathrm{Bu}$ ) karena taksa. Ketaksaan tuturan tersebut terbukti dari ketidakjelasan maksud ujarannya, apakah masing-masing mata pelajaran mendapatkan nilai 85 atau jumlah nilai kedua mata pelajaran tersebut adalah 85. Ketakjelasan maksud tutran Paino itu merupakan pelanggaran bidal cara. Seandainya berbunyi, "Ulangan basa Indonesia 50, matematika 35 Yung dadi jumlahe 85" (Ulangan bahasa Indonesia 50, matematika 35 Bu, jadi jumlahnya 85) tuturan Paino tidaklah melanggar bidal cara karena maksudnya jelas.

Pelanggaran bidal cara yang terjadi di dalam penggalan wacana (4) itu ternyata memiliki fungsi sebagai penunjang humor. Kelucuan yang tercipta dengan dukungan implikatur tuturan Paino di dalam penggalan wacana itu disebabkan oleh terjadinya pelanggaran bidal cara ini. Inferensi yang dilakukan terhadap pelanggaran bidal ini menghasilkan simpulan bahwa karena tidak mematuhi bidal ini, tuturan paino itu mengandung implikatur, yaitu membodohi. Implikatur membodohi dinyatakan secara tersirat olehnya melalui tuturan yang taksa. Paino bermaksud membodohi ibunya dengan mengatakan bahwa nilai ulangan mata pelajaran bahasa Indonesia dan matematikanya adalah 85 . 


\section{Pelanggaran Prinsip Kerukunan}

Prinsip kerukunan yang diajukan oleh Gunarwan (dalam Pranowo 2012:48) terdiri atas empat bidal, yaitu bidal kurmat (hormat), bidal andhap asor (rendah hati), bidal empan papan (sadar akan tempat), dan bidal tepa selira (tenggang rasa). Keempat jenis pelanggaran prinsip kerukunan tersebut dipaparkan secara rinci sesuai data penelitian sebagai berikut.

\section{Pelanggaran Bidal Kurmat (Hormat)}

\section{(5) KONTEKS}

: GUPLO SEDANG MENGENDARAI MOTOR, TIBA-TIBA SEORANG POLISI MENGHENTIKAN LAJU KENDARAANNYA KEMUDIAN MENANYAKAN SIM DAN STNK. GUPLO LUPA MEMBAWA SURAT-SURAT TERSEBUT, KARENA TAKUT DITILANG, IA MENYEBUT BAHWA AYAHNYA BEKERJA DI DITLANTAS KAPOLDA DAN MEMBERIKAN NOMER TELPONNYA.

: Iya, bener pak. Angger bapake ora percaya ya bapake telpun dhewek bae. Kiye nomere telpune.

Tya benar Pak. Kalau bapak tidak percaya, ini Bapak telpon sendiri saja. Ini nomor teleponnya.'

Krungu omongane Guplo si pulisi njenggirat kaget.

'Mendengar tuturan Guplo Polisi terperangah kaget.'

Polisi : Bapak kamu kerja di Ditlantas Polda?

Guplo : 'Iya, bener pak. Angger bapake ora percaya ya bapake telpun dhewek bae. Kiye nomere telpune.

(Iya, benar Pak. Kalau Bapak tidak percaya silahkan Bapak telpon sendiri saja. Ini nomor teleponnya.'

Guplo njuran ngulungna kertas sing ana tulisan nomer tilpune maring si polisi.

'Guplo kemudian menyerahkan kertas yang ada tulisan nomor telpon kepada Polisi.’

Polisi : Ya sudab pergi sana. Ngesuk aja maning-maning ora nggawa SIM ya!

'Ya sudah pergi sana. Besok lagi jangan lupa untuk tidak membawa SIM ya!'

Guplo : Kesunun Pak Pulisi!

'Terima kasih Pak Polisi'

Polisi : Kalo boleh tau, bapak di bagian apa ya?

Swara telpon : Ini di bagian kantin. Bapak mau pesan nasi berapa bungkus?”

Polisi : Asem, inyong kelombon gareng kiye tah.

'Asem, saya dibohongi gareng ini'

Tuturan Guplo dalam penggalan wacana (5) melanggar prinsip kerukunan bidal kurmat. Guplo menunjukkan rasa tidak hormat kepada Polisi dengan menggunakan ragam ngoko. Hal itu ditunjukkan ketika ia menjawab setiap pertanyaan dari Polisi. Dalam tuturan 
tersebut, Guplo menggunakan bahasa Jawa ragam ngoko. Padahal seharusnya Guplo menggunakan ragam krama karena mitra tuturnya orang yang lebih tua darinya dan memiliki jabatan, yaitu seorang polisi. Dengan menggunakan ragam ngoko, Guplo tidak menghormati mitra tuturnya. Seandainya Guplo menjawab "Nggih leres Pak, menawi Bapak. boten pitados, Bapak saged telpon piyambak" (Iya benar Pak. Kalau bapak tidak percaya, ini Bapak telpon sendiri saja. Ini nomor teleponnya) maka tidak akan melanggar bidal kurmat. Tuturan Guplo tersebut tidak melanggar bidal kurmat karena sudah menggunakan ragam krama.

Tuturan Guplo yang melanggar bidal kurmat itu memiliki fungsi sebagai sumber implikatur percakapan. Hal itu terjadi karena inferensi atas pelanggaran itu menghasilkan bahwa tuturan itu mengandung implikatur percakapan. Adapun implikatur tersebut adalah menyatakan bahwa ayah Guplo bekerja di Ditlantas Polda sebagai penjaga kantin.

\section{Pelanggaran Bidal Andhap Asor (Rendah Hati)}

Bidal andhap asor, berasal dari kata andhap (rendah) dan asor (berada di bawah). Bidal ini berisi nasihat agar orang selalu berperilaku rendah hati, tidak congkak, tidak tinggi hati, dan sebagainya. Dalam pemakaian bahasa, bidal ini berbunyi: Pakailah bahasa (dalam arti pilihlah kata-kata) sedemikian rupa sehingga Pt tahu bahwa Anda rendah hati atau tidak congkak. Bidal ini mempunyai subbidal: (1) pakailah bahasa sedemikian rupa sehingga $\mathrm{Pt}$ merasa bahwa ia dipuji dan (2) janganlah menggunakan honorifik untuk mengacu ke diri sendiri. Pelanggaran bidal andhap asor terdapat dalam penggalan wacana berikut.

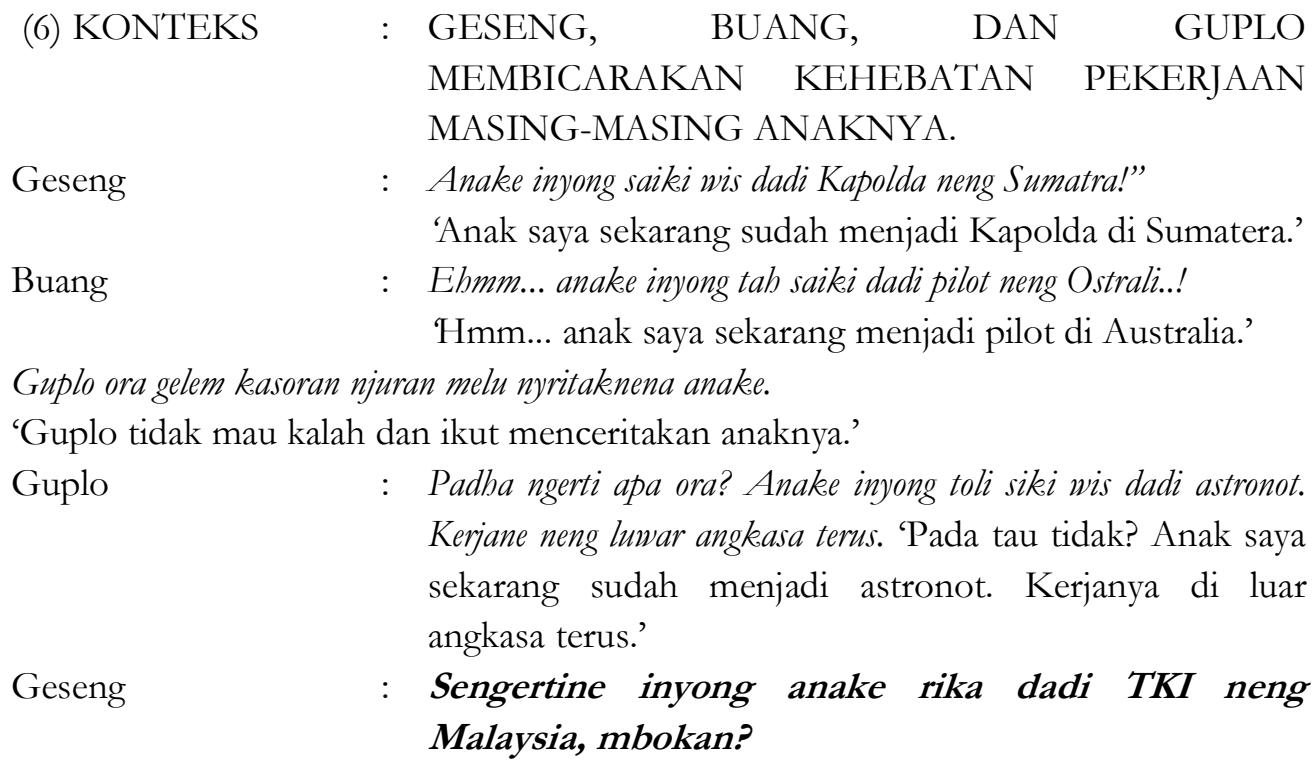

Setahu saya, anakmu jadi TKI di Malaysia.'

Pada penggalan wacana (6) tuturan Geseng melanggar bidal andhap asor karena menunjukkan ketidaksopanan dengan tidak bersikap rendah hati. Tuturan geseng Sengertine inyong anake rika dadi TKI neng Malaysia, mbokan? (Setahu saya, anakmu jadi TKI di Malaysia) bertujuan merendahkan Guplo, mitra tuturnya padahal bidal ini mengharuskan untuk selalu berperilaku rendah hati. Geseng merendahkan mitra tuturnya, Guplo karena menghina Guplo dengan menyebutkan bahwa anaknya hanya seorang TKI di Malaysia. tuturan 
Geseng memiliki fungsi sebagai sumber implikatur percakapan. Hal itu terjadi karena inferensi atas pelanggaran bidal itu menghasilkan implikatur. Implikatur dari Tuturan Geseng adalah mengejek mitra tuturnya (guplo) yang anaknya hanya seorang TKI.

\section{Pelanggaran Bidal Empan Papan (Sadar akan Tempat)}

Kata empan yang berasal dari kata papan mempunyai arti 'tempat' atau 'posisi'. Bidal ini berisi nasihat agar orang pandai-pandai membawa diri atau menyadari kedudukan dirinya sebagai anggota masyarakat. Bidal ini menasihati agar orang menempati kedudukan yang sudah ditetapkan untuk dirinya dan tidak berpindah kedudukan karena hal itu akan mengusik keseimbangan. Pelanggaran bidal empan papan terdapat dalam penggalan wacana berikut.

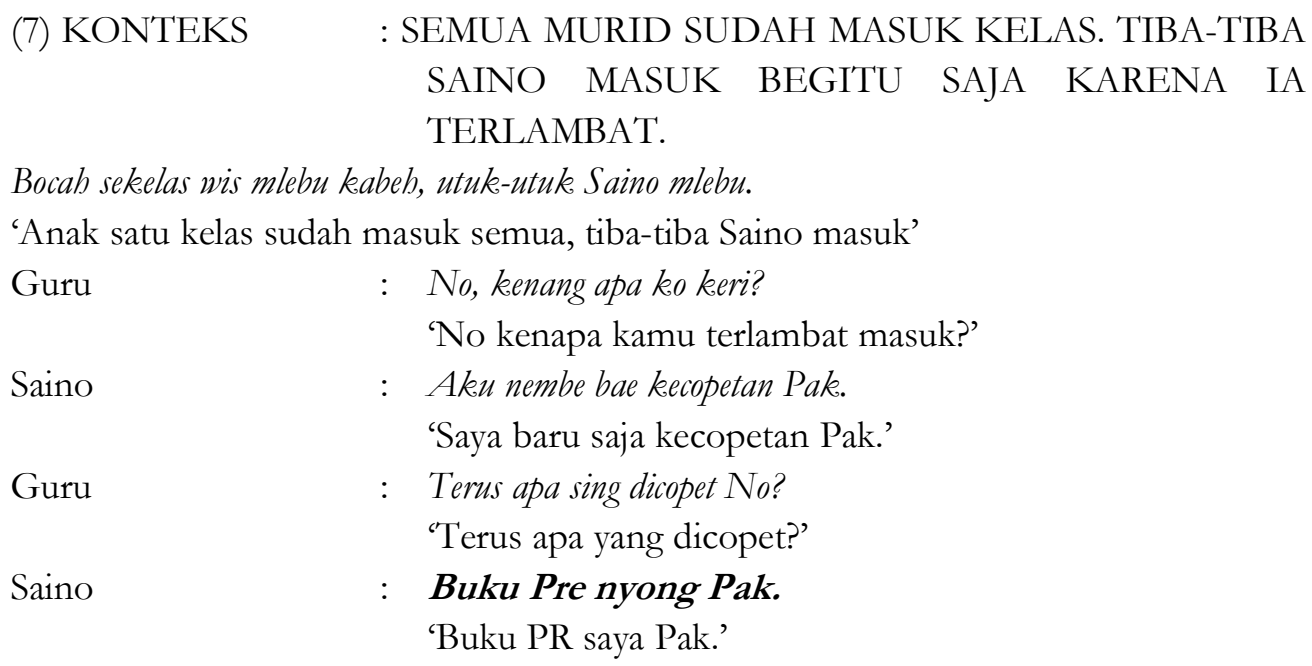

Tuturan Saino "Buku PR e nyong Pak." dalam penggalan wacana (7) melanggar prinsip kerukunan bidal empan papan (menempatkan diri). Seharusnya, bahasa yang digunakan Saino adalah ragam krama bukan ngoko. Dalam tradisi Jawa, ketika orang yang lebih muda berbicara dengan orang yang lebih tua, maka menggunakan ragam krama. Hal ini bertujuan untuk memberikan rasa hormat kepada orang yang lebih tua. Akan tetapi, dalam tuturan tersebut, Saino menggunakan ragam ngoko. Hal ini tentu saja tidak empan papan. Saino dianggap tidak bisa menempatkan diri karena lawan bicaranya adalah orang yang lebih tua sekaligus gurunya. Oleh karena itu, tuturan Saino melanggar prinsip kerukunan bidal empan papan. Tuturan Saino melangar bidal empan papan karena yang digunakan adalah ragam ngoko bukan krama. Ragam krama seharusnya digunakan Saino untuk menjawab pertanyaan mitra tuturnya (guru) karena merupakan orang yang lebih tua sekaligus sebagai gurunya.

Tuturan Saino berfungsi sebagai sumber implikatur percakapan. Hal itu terjadi karena inferensi atas pelanggaran bidal itu menghasilkan implikatur. Implikatur dari tuturan Saino adalah bahwa ia belum mengerjakan PR.

\section{Pelanggaran Bidal Tepa Selira (Tenggang Rasa)}


Tepa selira berasal dari tepak yang berarti kena dan kata slira yang berarti tubuh. Tepa selira diartikan sebagai ukurlah tubuh sendiri. Bidal ini menasehati agar orang tidak melakukan sesuatu kepada orang lain yang dia sendiri tidak mau orang lain melakukan sesuatu itu kepada dirinya. Dalam berbahasa, bidal ini berbunyi: jangan gunakan bahasa yang tidak patut kepada orang lain sebagimana Anda tidak mau orang lain menggunakan bahasa yang tidak patut itu kepada Anda. Bidal ini mempunyai subbidal: (1) pakailah bahasa yang patut kepada orang lain sebagaimana Anda mau orang lain menggunakan bahasa yang patut kepada Anda dan (2) hindari penggunaan bahasa yang tidak patut. Pelanggaran bidal tepa selira terdapat dalam penggalan wacana berikut.

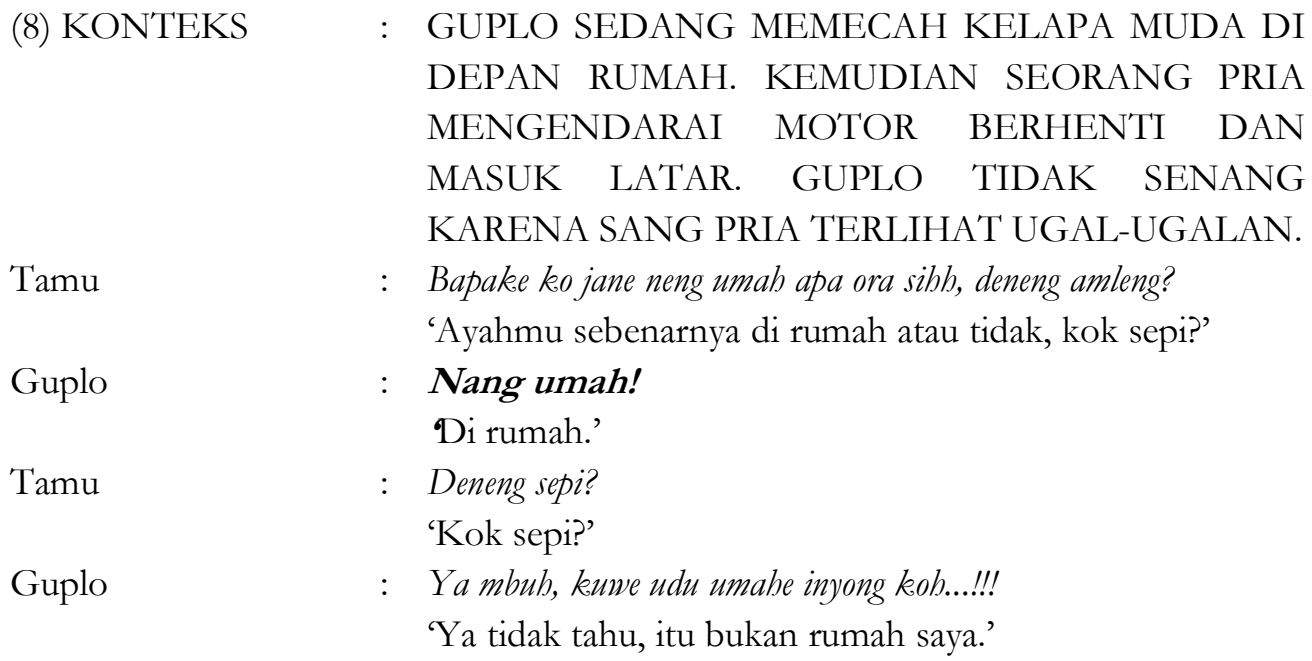

Tuturan Guplo dalam penggalan wacana (8) melanggar bidal tepa selira karena Guplo menggunakan bahasa yang tidak patut terhadap tamunya. Selain itu, Guplo seharusnya menawarkan kepada tamunya untuk mampir (masuk) ke dalam rumahnya. Hal tersebut menunjukkan bahwa dalam kehidupan sosial Guplo ia belum menggunakan bidal tepa selira. Apabila Guplo mempersilakan tamunya untuk masuk ke dalam rumahnya, "Mangga Mas, pinarak riyin" (Mari mas, silakan masuk) maka ia sudah menggunakan bidal tepa selira dalam kehidupan sosialnya. Tuturan Guplo berfungsi sebagai sumber implikatur percakapan. Hal itu terjadi karena inferensi atas pelanggaran bidal itu menghasilkan implikatur. Implikatur dari tuturan Guplo adalah menunjukkan ketidaksukaan Guplo terhadap tamunya sehingga Guplo tidak mau memberi tahu dengan jelas letak rumahnya.

\section{SIMPULAN}

Berdasarkan hasil penelitian terhadap penyebab implikatur percakapan implikatur pada wacana humor berbahasa Jawa rubrik Thengil di majalah Ancas, maka dapat disimpulkan penyebab implikatur yang ditemukan adalah (1) pelanggaran bidal kuantitas, (2) pelanggaran bidal kualitas, (3) pelanggaran bidal relevansi, dan (4) pelanggaran bidal cara. Pelanggaran prinsip kerukunan yang ditemukan adalah (1) pelanggaran bidal kurmat, (2) pelanggaran bidal andhap asor, (3) pelanggaran bidal empan papan, dan (4) pelanggaran bidal tepa selira. 


\section{DAFTAR PUSTAKA}

Gunarwan, Asim. 2007. PELLBA 18: Pertemuan Linguistik Lembaga Bahasa Atma Jaya: Kedelapanbelas. Bahasa dan Budaya. Jakarta: Yayasan Obor Indonesia.

Grice, H. Paul. 1975. "Logic and Conversation". Pragmatics: A Readers (Cole, Dater dan S. Morgan ed.). New York: Oxford University Press.

Leech, Geoffrey. 1993. Prinsip-Prinsip Pragmatik. Terjemahan Dr. M.D.D. Oka, M. A. Jakarta: UI Press.

Pranowo. 2012. Berbahasa Secara Santun. Yogyakarta: Pustaka Pelajar.

Rustono. 1999. Pokok-pokok Pragmatik. Semarang: IKIP Semarang.

Suseno, Frans Magnis. 1984. Etika Jawa. Jakarta: Gramedia

Wijana, I Dewa Putu. 2002. Pragmatik, Teori, dan Analisis. Yogyakarta: Lingkar Media Jogja. 